\title{
Relationship between Frequency Dependence of Lung Compliance and Distribution of Ventilation
}

\author{
Adam Wanner, Stephen Zarzecki, Neal Atkins, Angel Zapata, and \\ MARVIN A. SACKNER \\ From the Division of Pulmonary Disease, Department of Medicine, Mount Sinai \\ Medical Center, Miami Beach, Florida 33140
}

\begin{abstract}
The previously demonstrated empirical association between frequency dependence of lung compliance and distribution of ventilation, the latter determined by the $\mathrm{N}_{2}$ washout technique, was confirmed by establishing a mathematical link between the two tests. By assuming a two-compartment system with known compliances and making corrections for Pendelluft and common dead space mixing effects, the ratio of dynamic to static compliance $\left(C_{\mathrm{dyn}} / C_{\mathrm{st}}\right)$ for any respiratory frequency can be calculated from the compartmental analysis of the $\mathrm{N}_{2}$ washout at a single respiratory frequency. By using these equations, a good correlation was found between calculated and measured $C_{\mathrm{dyn}} / C_{\mathrm{st}}$ in dogs with artificially induced bronchial obstruction and in young smokers or young nonsmokers after carbachol inhalation. A two-compartment $\mathrm{N}_{2}$ washout was demonstrated in 10 young healthy smokers at one or two respiratory frequencies whereas all 10 normal controls showed a single exponential curve. These findings indicate that the noninvasive $\mathrm{N}_{2}$ washout test is capable of predicting $C_{\mathrm{dyn}} / C_{\mathrm{st}}$ and at the same time gives a direct measure of gas distribution. Further, it appears to be a highly sensitive method for the detection of "small airway disease."
\end{abstract}

\section{INTRODUCTION}

It has been convincingly demonstrated in the electrical analog of the lung (1) as well as in human experiments (2) that unequal time constants among parallel pulmonary units produce frequency dependence of lung compliance. Defares and Donleben (3) deduced that unequal time constants lead to uneven ventilation when the ratios of compartmental tidal volumes to respective compartmental volumes are different. A

Received for publication 24 July 1973 and in revised form 11 July 1974. tendency towards a rate-dependent decrease in dynamic lung compliance was demonstrated by Chiang (4) in healthy adolescents with nonuniform distribution of ventilation as measured by a $\mathrm{N}_{2}$ washout technique. Ingram and Schilder (5) found that distribution of ventilation became more uneven as dynamic lung compliance $\left(C_{\mathrm{dyn}}\right)$ decreased with increasing respiratory rates in smokers and patients with mild obstructive lung disease. Recently, Chiang (6) established that the mechanical time constant for the whole lung was closely related to a time constant derived from analysis of the $\mathrm{N}_{2}$ washout curve. Thus, frequency dependence of lung compliance appears to be associated with rate-dependent changes in distribution of ventilation. If it is possible to predict frequency dependence of lung compliance from analysis of the $\mathrm{N}_{2}$ washout curve, then the latter test can be substituted for the difficult, timeconsuming and invasive lung compliance test, a present standard for detection of small airway disease (2).

The purpose of the present investigation was $(a)$ to develop a mathematical two-compartment analog of the lung to relate the equations of Otis and his associates (1) for dynamic lung compliance to the equations of Fowler, Cornish, and Kety (7) for $\mathrm{N}_{2}$ washout, and $(b)$ to test these equations while simultaneously measuring dynamic compliance and $\mathrm{N}_{2}$ washout in dogs with mechanically induced bronchial obstruction, in humans with pharmacologically induced bronchoconstriction, and in young smokers.

\section{THEORETICAL CONSIDERATIONS}

The relationship between frequency dependence of lung compliance, or any appreciable decrease in dynamic compliance with increasing breathing frequency, and uneven distribution of ventilation has been investigated by Defares and Donleben (3). They demonstrated that frequency dependence of lung compliance is not always associated with uneven distribution of ventilation at a given respiratory rate. This is because frequency dependence of compliance is a reflection of differences in impedance of parallel compartments in the lung 
and, therefore, of differences in the tidal volumes of these compartments, while the criteria for uneven distribution of ventilation includes not only the distribution of compartmental tidal volumes, but also the distribution of compartmental volumes, or, for the two-compartment model:

$$
\frac{V_{T_{1}}}{V_{1}} \neq \frac{V_{T_{2}}}{V_{2}}
$$

where $V_{1}=n_{1} V_{L}$ and $V_{2}=n_{2} V_{L}\left(n_{1}\right.$ and $n_{2}$ are the fractional volumes of the compartments and $V_{\mathrm{L}}$ is the lung volume). To clarify we will consider the following situations: $(a)$ the elastic properties of the lung are normal (i.e., $C_{1} / V_{1}=C_{2} / V_{2}$, $C_{1}=n_{1} C_{\mathrm{st}}$, and $C_{2}=n_{2} C_{\mathrm{st}}$, where $C_{1}$ and $C_{2}$ are the compartmental compliances, and $C_{s t}$ is the static compliance of the lung) and the compartmental $R C$ time constants are equal, $(b)$ normal elastic properties, but unequal compartmental time constants, $(c)$ altered elastic properties of the lung $\left(C_{1} / V_{1} \neq\right.$ $\left.C_{2} / V_{2}\right)$ and unequal time constants, and $(d)$ altered elastic properties and equal time constants.

In the first situation, which describes the normal healthy lung, distribution of ventilation will be uniform and lung compliance will not change with respiratory frequency. In the second case, frequency dependence of lung compliance due to unequal time constants will be associated with uneven distribution of ventilation as detected by the multiple breath $\mathrm{N}_{2}$ washout at all respiratory frequencies. This is probably true for the majority of patients with early obstructive airway disease. In the third situation, frequency dependence of lung compliance will be present due to unequal time constants, but distribution of ventilation may be uniform at a single respiratory frequency. However, uneven distribution of ventilation will occur at all other respiratory frequencies. This is illustrated in Fig. 1 which compares such a pattern (Fig. 1A) to normal elastic properties with unequal time constants (Fig. 1B). Finally, the fourth situation is the uncommon occurrence of a corresponding change in airway resistance to match the change in compartmental compliance due to altered elastic properties in such a way as to make the $R C$ time constants equal. Here, the distribution of ventilation may be uneven while lung compliance is not frequency dependent.

For all practical purposes, uneven distribution of ventilation should be associated with frequency dependence of lung compliance, whereas, even distribution of ventilation determined at a single breathing frequency could indicate either absence of frequency dependence of compliance, or the special case of frequency dependence of lung compliance with altered elastic properties of the compartments. Consequently, to be certain that lung compliance is not frequency dependent, the $\mathrm{N}_{2}$ washout analysis must be performed at at least two frequencies. If at both frequencies the $\mathrm{N}_{2}$ washout curves are single exponentials, it may be assumed that distribution is even for all frequencies and that the dynamic lung compliance is not frequency dependent. A single exponential curve at one frequency but not at another will indicate frequency dependence of compliance with altered compartmental elastic properties, unless the single exponential curve is due to insensitivity of the $\mathrm{N}_{2}$ washout method to multiple compartments at lower frequencies or trapping of gas at higher frequencies. The dynamic compliance is a precise indicator of distribution of ventilation only when the compartmental volumes are known. However, in the presence of unequal time constants where $T_{2} / T_{1}$ is above a threshold value of approximately 10 , uneven distribution of ventilation can be demonstrated regardless of compartmental volume by the $\mathrm{N}_{2}$ washout procedure if multiple breathing frequencies are employed. In this mathematical treatment we have assumed
A

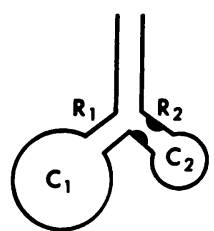

$n_{1}=0.7 \quad n_{2}=0.3$

$R_{1}=0.71 \quad R_{2}=11.7$

$C_{1}=0.03 \quad C_{2}=0.06$

$T_{1}=0.02 \quad T_{2}=0.70$
B

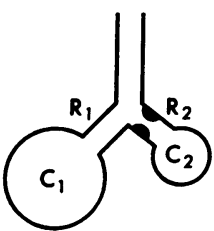

$n_{1}=0.7 \quad n_{2}=0.3$

$R_{1}=0.71 \quad R_{2}=11.7$

$C_{1}=0.14 \quad C_{2}=0.06$

$T_{1}=0.10 \quad T_{2}=0.70$

FIGURE 1 Example of even distribution of ventilation with uneven time constants. $(A) T_{1} \neq T_{2}$, but at 60 breaths $/ \mathrm{min}$, distribution of ventilation is even. This is the case of altered compartmental elastic properties. $(B) T_{1} \neq T_{2}$, and, since elastic properties are unchanged, distribution of ventilation is uneven at all breathing frequencies. (C) Otis' (1) two compartment R-C model.

Otis' two-compartment model of the lung (1) for simplicity (Fig. 1C); however, the treatment is readily extended to an n-compartmental model.

Otis et al. (1) assumed a two-compartment model of the lung and derived expressions for the dynamic lung compliance and for the tidal volumes of the two compartments. These expressions, rearranged are:

$$
\begin{gathered}
C_{\mathrm{dyn}}=\frac{\omega^{2}\left(T_{2} C_{1}+T_{1} C_{2}\right)^{2}+\left(C_{1}+C_{2}\right)^{2}}{\omega^{2}\left(T_{1}^{2} C_{2}+T_{2}^{2} C_{1}\right)+\left(C_{1}+C_{2}\right)} \\
V_{T_{1}}=V_{T} Z_{T} / Z_{1} \\
V_{T_{2}}=V_{T} Z_{T} / Z_{2}
\end{gathered}
$$

where $\omega=2 \pi \times$ frequency; $C_{1}, C_{2}=$ compartmental compliances; $T_{1}, T_{2}=R_{1} C_{1}, R_{2} C_{2}=$ compartmental $R C$ time constants; $Z_{T}=$ total impedance of the lung; $Z_{1}, Z_{2}=$ compartmental impedances; and $V_{T}=$ tidal volume.

Now since

$$
Z=\left(R^{2}+\frac{1}{\omega^{2} C^{2}}\right)^{\frac{1}{2}}=\frac{1}{C}\left(T^{2}+\frac{1}{\omega^{2}}\right)^{\frac{1}{2}}
$$

eqs. 3 and 4 can be written

$$
\begin{aligned}
& \frac{V_{T_{1}}}{V_{T}}=\frac{\frac{1}{C_{2}}\left(T_{2}^{2}+\frac{1}{\omega^{2}}\right)^{\frac{1}{2}}}{\left(\frac{T_{1}^{2}+\frac{1}{\omega^{2}}}{C_{1}{ }^{2}}+\frac{T_{2}^{2}+\frac{1}{\omega^{2}}}{C_{2}{ }^{2}}+2 \frac{T_{1} T_{2}+\frac{1}{\omega^{2}}}{C_{1} C_{2}}\right)^{\frac{1}{2}}} \\
& \frac{V_{T_{2}}}{V_{T}}=\frac{\frac{1}{C_{1}}\left(T_{1}{ }^{2}+\frac{1}{\omega^{2}}\right)^{\frac{1}{2}}}{\left(\frac{T_{1}{ }^{2}+\frac{1}{\omega^{2}}}{C_{1}{ }^{2}}+\frac{T_{2}{ }^{2}+\frac{1}{\omega^{2}}}{C_{2}{ }^{2}}+2-\frac{T_{1} T_{2}+\frac{1}{\omega^{2}}}{C_{1} C_{2}}\right)^{\frac{1}{2}}}
\end{aligned}
$$

If we assume that the elastic properties of the two compartments are the same, as is probably true for healthy subjects 
and those with early obstructive airway disease, then $C_{1}=n_{1} C_{\text {st }}$, and $C_{2}=n_{2} C_{\text {st }}$ (Fig. 1B). Therefore, now Eqs. 2, 6 , and 7 can be reduced to:

$$
\begin{aligned}
& \frac{C_{\mathrm{dyn}}}{C_{\mathrm{st}}}=\frac{\omega^{2}\left(n_{2} T_{1}+n_{1} T_{2}\right)^{2}+1}{\omega^{2}\left(n_{2} T_{1}^{2}+n_{1} T_{2}^{2}\right)+1} \\
& \frac{V_{T_{1}}}{V_{T}}=\frac{n_{1}\left(T_{2}^{2}+\frac{1}{\omega^{2}}\right)^{\frac{1}{2}}}{\left[\left(n_{2} T_{1}+n_{1} T_{2}\right)^{2}+\frac{1}{\omega^{2}}\right]^{\frac{1}{2}}} \\
& \frac{V_{T_{2}}}{V_{T}}=\frac{n_{2}\left(T_{1}^{2}+\frac{1}{\omega^{2}}\right)^{\frac{1}{2}}}{\left[\left(n_{2} T_{1}+n_{1} T_{2}\right)^{2}+\frac{1}{\omega^{2}}\right]^{\frac{1}{2}}}
\end{aligned}
$$

From Eqs. 9 and 10, if the ratios $V_{T_{1}} / V_{T}$ and $V_{T_{2}} / V_{T}$ are known for a given respiratory frequency and the fractional volumes $n_{1}$ and $n_{2}$ are known, the two equations can be solved simultaneously for $T_{1}$ and $T_{2}$ and by substituting these values into $\mathrm{Eq} .8$ and varying $\omega$, the rationalized dynamic compliance can be predicted as a function of frequency.

The analysis of the $\mathrm{N}_{2}$ washout curve (7) gives data which with certain assumptions yield values for the fractional volumes and a close approximation of the ratios $V_{T_{1}} / V_{T}$ and $V_{T_{2}} / V_{T}$. The latter are based upon the ratios of the compartmental alveolar ventilations to the total alveolar ventilation, $\dot{V}_{A_{1}} / \dot{V}_{A}$ and $\dot{V}_{A_{2}} / \dot{V}_{A}$. If the dead space of the lung is evenly distributed and the tidal volume is large relative to the compartmental dead space these ratios approximate the ratios of the tidal volumes, or

$$
\frac{V_{T_{1}}}{V_{T}} \simeq \frac{\dot{V}_{A_{1}}}{\dot{V}_{A}} \quad \frac{V_{T_{2}}}{V_{T}} \simeq \frac{\dot{V}_{A_{2}}}{\dot{V}_{A}}
$$

The values for alveolar ventilation of the two compartments as derived by the analysis of Fowler and associates (7) are not entirely accurate. The bidirectional gas transfer between compartments due to Pendelluft and common dead space mixing is responsible for an underestimation of the ventilation of the "fast" compartment, and a slight overestimation of the ventilation of the "slow" compartment. In order to obtain more accuracy in the determination of the ratios $\dot{V}_{A_{1}} / \dot{V}_{A}$ and $\dot{V}_{A_{2}} / \dot{V}_{A}$, appropriate corrections must be applied. Safonoff and Emmanuel (8) reported that the error in the ventilation of the slow compartment is minimal and can be neglected in the range of interest. They estimated that the volume of gas transfer due to Pendelluft and common dead space mixing is approximately $60 \%$ of the tidal volume of the slow compartment (see Appendix A). Thus,

$$
V_{T}=V_{T_{1}}+V_{T_{2}}-V_{p}
$$

where $V_{p}=$ the volume of gas transfer due to Pendelluft and common dead space mixing. But $V_{p}=0.60 \times V_{T_{2}}$, where $V_{T_{2}}$ is the tidal volume of the slow compartment. Then

$$
V_{T}=V_{T_{1}}+0.4 V_{T_{2}}
$$

Now, since $\dot{V}_{A}=\left(V_{T}-V_{D}\right) \times$ frequency $(f)$, where $V_{D}=$ dead space volume, or $V_{T}=\left(\dot{V}_{A} / f\right)+V_{D}$.

$$
\frac{\dot{V}_{A}}{f}+V_{D}=\frac{\dot{V}_{A_{1}}}{f}+V_{D_{1}}+0.40\left(\frac{\dot{V}_{A_{2}}}{f}+V_{D_{2}}\right)
$$

which reduces to

$$
\dot{V}_{A}+\left(V_{D}-V_{D_{1}}-0.40 V_{D_{2}}\right) f=\dot{V}_{A_{1}}+0.40 \dot{V}_{A_{2}}
$$

If it is assumed that $\left(V_{D}-V_{D_{1}}-0.40 V_{D_{2}}\right) \ll V_{T}$, then $\dot{V}_{A} \simeq \dot{V}_{A_{1}}+0.40 \dot{V}_{A_{2}}$ and, since the error in $\dot{V}_{A_{2}}$ can be neglected (8), this approximation can be used to correct the ventilation of the fast compartment, $\dot{V}_{A_{1}}$,

$$
\dot{V}_{A_{1}}=\dot{V}_{A}-0.40 \dot{V}_{A_{2}}
$$

By substituting the corrected values for the ventilation ratios into Eqs. 9 and 10 along with the frequency at which these ratios were determined, $T_{1}$ and $T_{2}$ can be solved. The solutions are:

$$
\begin{aligned}
& T_{1}=\frac{\left\{B\left[\frac{\left(Y^{2}+4\right) Z^{\frac{1}{2}}-Y}{2}\right]+A\right\}^{\frac{1}{2}}}{n_{2}} \\
& T_{2}=\frac{\left[\frac{\left(Y^{2}+4 Z\right)^{\frac{1}{2}}-Y}{2}\right]^{\frac{1}{2}}}{n_{1}}
\end{aligned}
$$

where

$$
\begin{aligned}
& A=\frac{\dot{V}_{A_{2}}{ }^{2}}{\omega^{2}}\left(\frac{n_{1}{ }^{2}}{\dot{V}_{A_{1}}{ }^{2}}-\frac{n_{2}{ }^{2}}{\dot{V}_{A_{2}}{ }^{2}}\right) \\
& B=\left(\frac{\dot{V}_{A_{2}}}{\dot{V}_{A_{1}}}\right)^{2} \\
& Y=\frac{A+\left(\frac{n_{1}{ }^{2} \dot{V}_{A}}{\dot{V}_{A_{1}}{ }^{2} \omega^{2}}-\frac{1}{\omega^{2}}-A\right)\left(\frac{B}{2}-\frac{\dot{V}_{A}{ }^{2}}{2 \dot{V}_{A_{1}}{ }^{2}}+\frac{1}{2}\right)}{B-\left(\frac{B}{2}-\frac{\dot{V}_{A}{ }^{2}}{2 \dot{V}_{A_{1}}{ }^{2}}+\frac{1}{2}\right)^{2}} \\
& \nearrow=\frac{-\left(\frac{n_{1}{ }^{2} \dot{V}_{A}{ }^{2}}{\dot{V}_{A_{1}}{ }^{2} \omega^{2}}-\frac{1}{\omega^{2}}\right)^{2}}{B-\left(\frac{B}{2}-\frac{\dot{V}_{A}{ }^{2}}{2 \dot{V}_{A_{1}}{ }^{2}}+\frac{1}{2}\right)^{2}}
\end{aligned}
$$

Substituting these values for $T_{1}$ and $T_{2}$ into Eq. 8 enables us to generate a plot of rationalized dynamic compliance versus frequency. The accuracy of the approximation of $V_{p} / V_{T_{2}}=0.60$ is handled in Appendix $\mathrm{A}$ and a complete derivation of the expressions for $T_{1}$ and $T_{2}$ is given in Appen$\operatorname{dix}$ B.

\section{METHODS}

Animal experiments. Ten mongrel dogs weighing between 12 and $30 \mathrm{~kg}$ were anesthetized with sodium pentobarbital $50 \mathrm{mg} / \mathrm{kg}$, intubated with a cuffed endotracheal tube and suspended in the prone position. Ventilation was controlled by a Harvard Animal Respirator (Harvard Apparatus Co., Inc., Millis, Mass.) with a fixed tidal volume of $0.2-0.4$ liters adjusted according to the weight of the dog and an inspiration to expiration ratio of $1: 1$. A balloon catheter as described by Milic-Emili, Mead, Turner, and Glauser (9) was placed in the lower esophagus and transpulmonary pressure estimated with a differential gauge (DP-9 Validyne, Northridge, Calif.) by referencing espohageal pressure to mouth pressure. At frequencies up to $90 / \mathrm{min}$ and with flow rates in the range used 
in the experiments, no phase shift was detected in this system. Between the inspiratory and expiratory part of the respiratory part of the respirator and the T-adaptor at the downstream end of the endotracheal tube, two three-way valves were incorporated so that the dog's airway could be occluded at any instant of the respiratory cycle. A dynamically balanced Fleisch no. 0 pneumotachograph connected to a Validyne DP-7 transducer was inserted between the endotracheal tube and the T-adaptor to obtain points of zero flow for the calculation of dynamic compliance. All pressure transducers used demonstrated a common mode rejection ratio of greater than $64 \mathrm{~dB}$ below $3 \mathrm{~Hz}$. Nitrogen concentration was measured upstream of the T-adaptor with a rapidly responding analyzer (Nitralyzer, Med Science Electronics, Inc., St. Louis, Mo.). Expiratory flow was recorded from the expiratory line of the breathing system with a dynamically balanced Fleisch no. 1 pneumotachograph which was linear to flow rates of 60 liter/ min. Flow was electrically integrated to obtain tidal volume. All signals were recorded on a Grass Polygraph recorder (model 78B, Grass Instrument Co., Quincy, Mass.).

The tests were conducted as follows: First, the animal was ventilated with room air until a stable end-expiratory volume level was reached. At this point, the animal's airway was occluded by turning the two three-way valves, and $100 \% \mathrm{O}_{2}$ was introduced into the respirator, thereby providing an inspiratory $\mathrm{N}_{2}$ concentration of less than $0.3 \%$. After 5 cycles during which time the inspiratory lines of the respirator were cleared of $\mathrm{N}_{2}$, the valves were again turned and the $\mathrm{N}_{2}$ washout started. The test was terminated when end-tidal $\mathrm{N}_{2}$ concentration was below $1 \%$. The range of lung volumes for comparison of the dynamic to static lung compliance was the same.

Nitrogen washout and dynamic compliance measurements were performed at respiratory frequencies of $20,30,40$, and $50 / \mathrm{min}$ before and after partial obstruction of one main bronchus. The obstruction consisted of a metal tube, $2 \mathrm{~mm}$ in diameter and $10 \mathrm{~mm}$ long, surrounded by an inflatable cuff. It was placed in the right or left main bronchus immediately distal to the carina with a bronchoscopic forceps. Its location was ascertained by bronchofiberscopy. The cuff was inflated and the proximal end of the cuff catheter occluded with a plugged needle which was placed through the rubber adaptor of the endotracheal tube. Frequent tracheal suctioning was performed in order to prevent plugging of the obstruction with bronchial secretions. Before each run, the dog was given a deep breath by occluding the expiratory line. Static pressure volume curves were obtained by a stepwise inflation to 1.0 liter above functional residual capacity (FRC) and deflation to FRC with a calibrated giant syringe, after a sighing maneuver to 1.0 liters above FRC.

Human experiments. Three sets of experiments were conducted with human volunteers from whom informed consent was obtained. Two of these were designed to determine the relation between the dynamic lung compliance calculated from the $\mathrm{N}_{2}$ washout curves and the actually measured dynamic lung compliance (groups $\mathrm{A}$ and $\mathrm{B}$ ), while the third experiment (group C) was carried out to compare a number of commonly used pulmonary function tests for the detection of early lung disease between young healthy smokers and nonsmokers. All subjects were selected solely on the basis of their smoking history.

Nine healthy nonsmokers, ages 21-35 yr (group A) with normal routine pulmonary function tests as described below, performed $\mathrm{N}_{2}$ washouts at respiratory frequencies of 60 and $75 / \mathrm{min}$. Dynamic lung compliance measurements (at 20,40, and 60 breaths/min) and quasi-static pressure volume plots of the lung were obtained by the esophageal balloon catheter technique (9). Records of dynamic compliance were only accepted if end-expiratory volume did not change significantly during the run. Transpulmonary pressure was measured with a Validyne DP-9 differential transducer with a common mode rejection ratio of greater than $64 \mathrm{~dB}$ below $3 \mathrm{~Hz}$, and flow was measured by a dynamically balanced no. 1 Fleisch pneumotachograph connected to a Validyne DP-7 transducer. A slow inspiratory vital capacity maneuver followed by a slow expiratory vital capacity maneuver was done immediately before and after $\mathrm{N}_{2}$ washout and dynamic compliance determinations in order to ensure identical volume histories. These tests were performed in the control state and immediately after inhalation of $15-30$ breaths of $1.5 \%$ carbachol delivered through a D-30 generator (10). $\mathrm{N}_{2}$ washouts at two different frequencies and dynamic lung compliance were also obtained in nine healthy young smokers, ages 21-42 yr (group B) with normal routine pulmonary function tests. Finally, 10 young healthy nonsmokers and 10 smokers between the ages of 18 and $42 \mathrm{yr}$ (group C) were selected for estimation of distribution of ventilation by $\mathrm{N}_{2}$ washout at 60 and $75 \mathrm{breaths} / \mathrm{min}$. The smokers continued to smoke on the experiment day, but not within $1 \mathrm{~h}$ before the study. Routine pulmonary function studies were performed on all. The displaceable lung volumes were measured with a spirometer and functional residual capacity and airway resistance (panting at 1-2 cycles/s up to 0.5 liter/s inspiratory flow rate) with a body plethysmographic technic $(11,12)$. Single breath diffusing capacity (13), single breath nitrogen test (14), closing volume, and flow volume curves (15) were also obtained.

$\mathrm{N}_{2}$ washout was carried out with a breathing system analogous to the one used for the animal experiments. The nitrogen and volume signals were also displayed on an oscilloscope in order to guide the subject in maintaining an approximately constant end-expiratory volume throughout the test. A breath simulator (model 700, Somanetics Inc., La Jolla, Calif.) was used as auditory feedback for control of respiratory frequency.

Data analysis. Dynamic lung compliance was calculated by dividing the volume change by the transpulmonary pressure change between points of zero flow from end-inspiration to the beginning of the following inspiration. Static compliance was calculated on the deflation leg of the static pressure volume curve between pressure limits which were recorded during measurement of dynamic compliance. The $\mathrm{N}_{2}$ washout curves were analyzed on-line or from analog magnetic tape on a small digital computer (LINC 8, Digital Equipment Corp., Maynard, Mass.) (16). End-tidal $\mathrm{N}_{2}$ concentration was plotted against time (animals) and against cumulative expiratory volume (humans) and expressed as $\mathrm{N}_{2}$ clearance delay as described by Fowler et al. (7). Corrections for the excretion of tissue nitrogen were made according to Simmons and Hemmingway (17) in dogs and Bouhuys (18) in humans. Another correction was made for the $\mathrm{N}_{2}$ signal delay which was determined before the experiments. A computer program written in FOCAL was used to calculate frequency dependence of lung compliance from the compartmental analysis of nitrogen washout curve.

\section{RESULTS}

\section{Animal experiments}

No frequency dependence of $C_{\mathrm{dyn}}$ and a single compartment $\mathrm{N}_{2}$ washout occurred in all 10 dogs before unilateral bronchial obstruction, whereas after partial obstruction of one main bronchus, frequency dependence of $C_{\mathrm{dyn}}$ and $\mathrm{N}_{2}$ washout took place as expected 
(A)

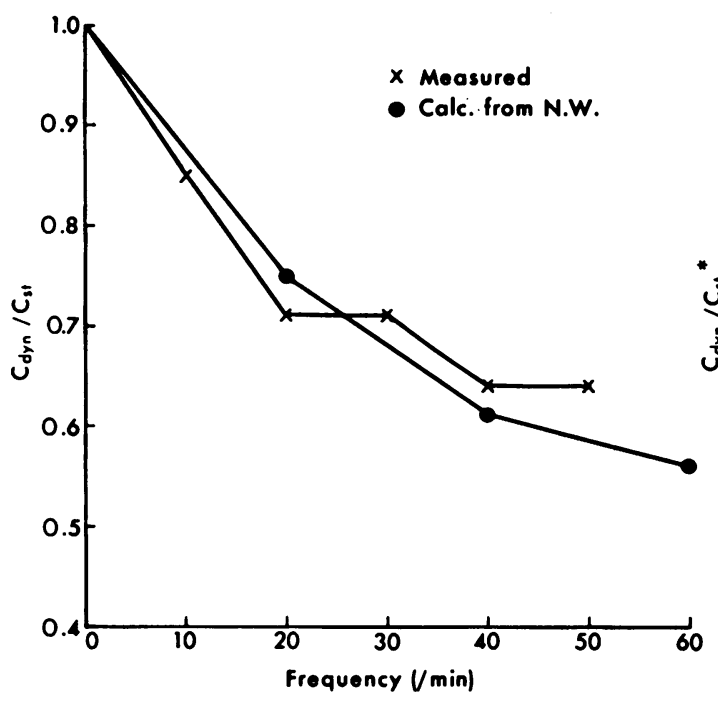

(B)

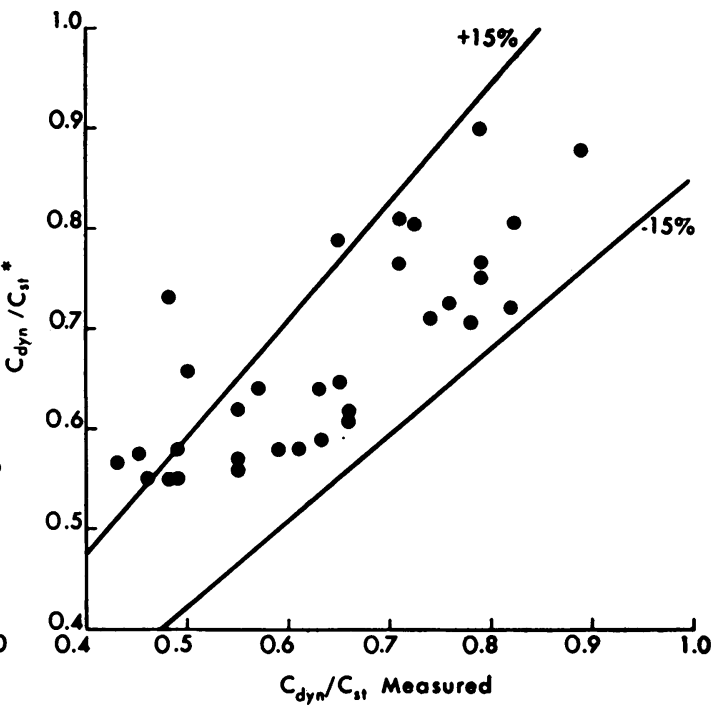

* Calculated from $\mathrm{N}_{2}$ Washout

FIGURE 2 Comparison of calculated (from $\mathrm{N}_{2}$ washout) and measured dynamic/static compliance $\left(C_{\mathrm{dyn}} / C_{\mathrm{st}}\right)$ in dogs with bronchial obstruction: $(A)$ A representative case showing calculated and measured $C_{\mathrm{dyn}} / C_{\mathrm{st}}$ as a function of respiratory frequency. $(B)$ Identity comparison of calculated and measured $C_{\mathrm{dyn}} / C_{\mathrm{st}}$ for all $10 \mathrm{dogs}$ at respiratory frequencies of 20,40 , and $60 / \mathrm{min}$.

from the theoretical predictions. Good agreement was found between $C_{\mathrm{dyn}} / C_{\mathrm{st}}$ calculated from the $\mathrm{N}_{2}$ washout at 50 breaths $/ \mathrm{min}$ and actually measured $C_{\mathrm{dyn}} / C_{\mathrm{st}}$ (Fig. 2). $85 \%$ of the points fell within $\pm 15 \%$ of the

(A)

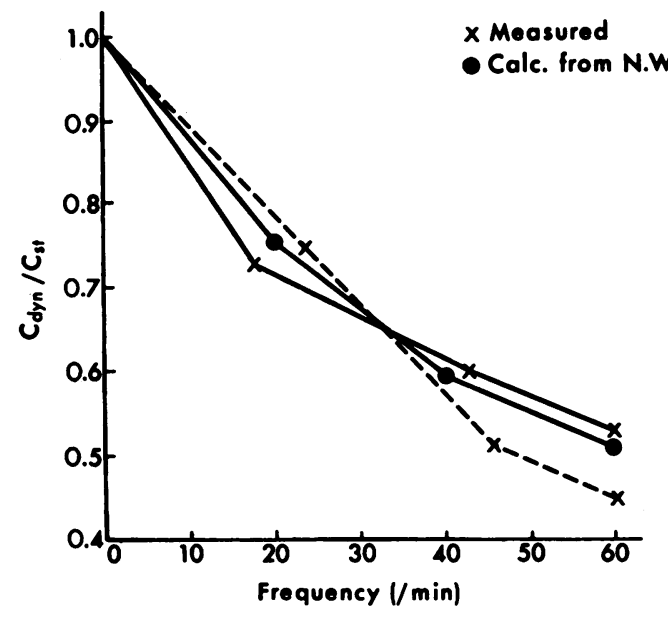

line of identity. As might be predicted, the ratio $C_{\mathrm{dyn}} / C_{\text {st }}$ leveled off at a value of 0.5 in this model, where the functional residual capacities of the obstructed and unobstructed lungs could be assumed to

FIGURE 3 Comparison of calculated (from $\mathrm{N}_{2}$ washout) and measured $C_{\mathrm{dyn}} / C_{\mathrm{st}}$ in normals following inhalation of carbachol (group A). $(A)$ A representative case showing calculated and measured $C_{\mathrm{dyn}} / C_{\mathrm{st}}$ as a function of respiratory frequency. Since respiratory frequency could not be precisely controlled during measurement of $C_{\mathrm{dyn}}$, an exponential curve was fitted to the measured points which were obtained in duplicate (solid and dotted lines) in order to allow comparison at any given respiratory rate. $(B)$ Identity comparison of calculated and measured $C_{\mathrm{dyn}} / C_{\mathrm{bt}}$ for all nine subjects at respiratory frequencies of 20,40 , and $60 / \mathrm{min}$.

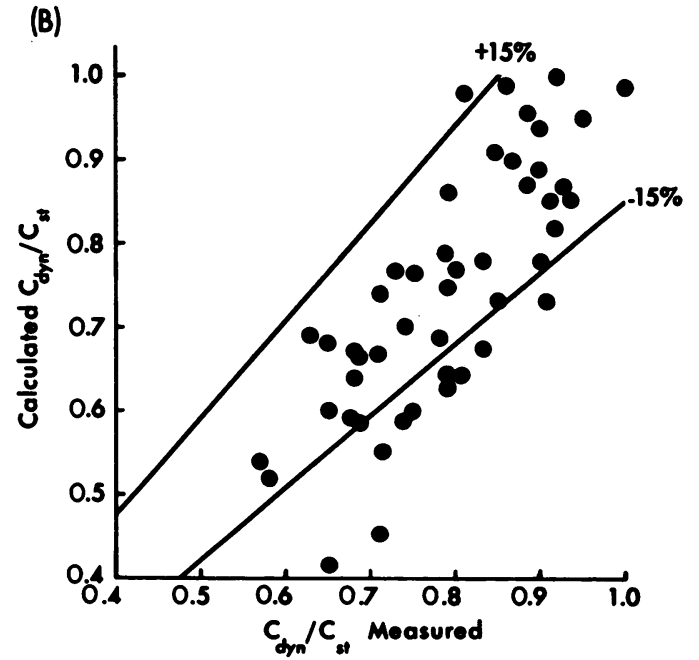


be approximately equal and the distribution of inspired air within each lung even. With this type of obstruction and respiratory frequencies up to $50 / \mathrm{min}$, we never observed a single compartment indicating complete gas trapping in the obstructive lung.

\section{Human experiments}

Group A. All nine subjects in this group of nonsmokers exhibited no frequency dependence of $C_{\mathrm{dyn}}$ and a single exponential $\mathrm{N}_{2}$ washout curve at 60 and 75 breaths/min in the control state, whereas the inhalation of carbachol produced definite changes in these two tests (Table 1A). A good agreement was demonstrated between calculated $C_{\mathrm{dyn}} / C_{\mathrm{st}}$ and actually measured $C_{\mathrm{dyn}} / C_{\mathrm{st}}$ in all subjects at respiratory frequencies of 20,40, and $60 / \mathrm{min}$ (Fig. 3).

Group $B$. The nine young smokers selected for this group had frequency dependence of $C_{\mathrm{dyn}}$ and exhibited two compartments in at least one of their $\mathrm{N}_{2}$ washout curves (Table 1B). Comparisons between calculated and measured $C_{\mathrm{dyn}} / C_{\mathrm{st}}$ at frequencies of 20,40 , and $60 / \mathrm{min}$ (Fig. 4) were similar to group A after carbachol administration. The smoking history in these subjects ranged from 1-40 packs/day yr.

Group C. The anthropometric characteristics, smoking history, symptoms, and the results of the routine pulmonary function tests of the 10 nonsmokers and 10 smokers are listed in Tables II and III. Predicted normal values were taken from Bates, Macklem, and Christie (19) and DuBois, Botelho, and Comroe (12). The two groups were matched with regard to age; the mean age of the smokers was $27.3 \mathrm{yr}$ (range 18-42) and of the nonsmokers $28.3 \mathrm{yr}$ (range 22-35). Seven smokers were asymptomatic, three gave a history of morning cough with sputum production, and one of these also had mild exertional dyspnea in the morning. None of the nonsmokers had respiratory symptoms. Conventional tests for detection of airway obstruction were within normal limits in both smokers and nonsmokers (Tables II and III). Fig. 5 compares the single breath nitrogen test, maximal flow at $50 \%$ vital capacity, and closing volume in smokers and nonsmokers. Although the differences were not significant for the single breath nitrogen test and closing volume, the maximum expiratory flow at $50 \%$ of vital capacity was significantly less in smokers (2.15 liters/s \pm 0.65$)$ than nonsmokers (3.25 liters $/ \mathrm{s} \pm 1.20)(P<0.05)$.

Distribution of ventilation as determined by the $\mathrm{N}_{2}$ washout technique was even at respiratory rates of 60 and $75 / \mathrm{min}$ in the 10 nonsmokers. The $\mathrm{N}_{2}$ clearance delay was $0 \%$ in all of them indicating that one compartment was present. On the other hand, all 10 smokers had two compartments in their $\mathrm{N}_{2}$ washout curves at at least one respiratory rate. In seven, an uneven dis-
TABLE I

Results of $\mathrm{N}_{2}$ Washout Analysis in Normals after Carbachol (Group A) and in Healthy Smokers (Group B)

\begin{tabular}{cccccccc}
\hline Subject & Freq & $\dot{V}_{A_{1}}$ & $\dot{V}_{A_{2}}$ & $n_{1}$ & $n_{2}$ & $T_{1}$ & $T_{2}$ \\
\hline \multicolumn{7}{c}{ A. Normals after carbachol } \\
1 & 70.8 & 16.9 & 10.3 & 0.30 & 0.70 & 0.04 & 0.4 \\
& 55.5 & 30.5 & 4.3 & 0.62 & 0.38 & 0.02 & 0.8 \\
2 & 73.0 & 12.9 & 5.3 & 0.44 & 0.56 & 0.001 & 0.5 \\
& 55.8 & 14.5 & 10.6 & 0.42 & 0.58 & 0.03 & 0.4 \\
3 & 72.3 & 27.3 & 6.3 & 0.59 & 0.41 & 0.003 & 0.4 \\
& 55.3 & 10.8 & 19.8 & 0.25 & 0.75 & 0.1 & 0.2 \\
4 & 73.5 & 18.4 & 8.8 & 0.49 & 0.51 & 0.02 & 0.3 \\
& - & - & - & - & - & - & - \\
5 & 73.2 & 26.9 & 6.4 & 0.52 & 0.48 & 0.01 & 0.4 \\
& 55.8 & 21.9 & 2.7 & 0.64 & 0.36 & 0.02 & 0.3 \\
6 & 73.3 & 21.9 & 9.7 & 0.44 & 0.56 & 0.004 & 0.4 \\
& - & - & - & - & - & - & - \\
7 & 71.7 & 16.0 & 21.5 & 0.24 & 0.76 & 0.06 & 0.2 \\
& 55.7 & 31.2 & 6.7 & 0.53 & 0.47 & 0.02 & 0.8 \\
8 & 72.2 & 4.4 & 13.8 & 0.03 & 0.97 & 0.02 & 1.1 \\
& 55.6 & 7.0 & 21.2 & 0.11 & 0.89 & 0.03 & 0.4 \\
9 & 73.9 & 19.4 & 5.2 & 0.45 & 0.55 & 0.02 & 0.7 \\
& 55.6 & 17.6 & 8.3 & 0.43 & 0.57 & 0.01 & 0.6
\end{tabular}

B. Healthy smokers

\begin{tabular}{rrrrrrrr}
1 & 74.0 & 4.5 & 15.7 & 0.09 & 0.91 & 0.01 & 0.3 \\
& \multicolumn{1}{c}{-} & - & - & - & - & - & - \\
& - & - & - & - & - & - & - \\
3 & 53.8 & 45.3 & 16.1 & 0.48 & 0.52 & 0.001 & 0.6 \\
& 67.1 & 9.7 & 9.2 & 0.29 & 0.71 & 0.02 & 0.5 \\
& 52.1 & 10.5 & 7.6 & 0.35 & 0.65 & 0.02 & 0.4 \\
4 & 70.8 & 7.0 & 6.5 & 0.34 & 0.66 & 0.02 & 0.4 \\
& 54.4 & 6.5 & 3.9 & 0.32 & 0.68 & 0.001 & 0.8 \\
5 & 73.7 & 36.4 & 4.5 & 0.56 & 0.44 & 0.03 & 0.9 \\
& 56.4 & 25.2 & 7.1 & 0.46 & 0.54 & 0.02 & 0.8 \\
6 & 73.5 & 6.6 & 12.9 & 0.19 & 0.81 & 0.05 & 0.2 \\
& 55.8 & 6.2 & 14.2 & 0.24 & 0.76 & 0.05 & 0.6 \\
7 & 71.0 & 15.8 & 16.0 & 0.17 & 0.83 & 0.03 & 0.4 \\
& 52.8 & 28.9 & 8.7 & 0.51 & 0.49 & 0.01 & 0.7 \\
8 & 70.6 & 16.0 & 5.8 & 0.53 & 0.47 & 0.01 & 0.4 \\
& 56.3 & 19.6 & 2.2 & 0.74 & 0.26 & 0.01 & 0.6 \\
9 & 71.1 & 59.9 & 15.2 & 0.52 & 0.48 & 0.01 & 0.4 \\
& 55.5 & 11.0 & 27.7 & 0.15 & 0.85 & 0.05 & 0.3
\end{tabular}

Freq, respiratory frequency; $\dot{V}_{A_{1}}$ and $\dot{V}_{A_{2}}$, compartmental alveolar ventilations; $n_{1}$ and $n_{2}$, fractional compartmental volumes; $T_{1}$ and $T_{2}$, compartmental time constants calculated from $\mathrm{N}_{2}$ washout results. 

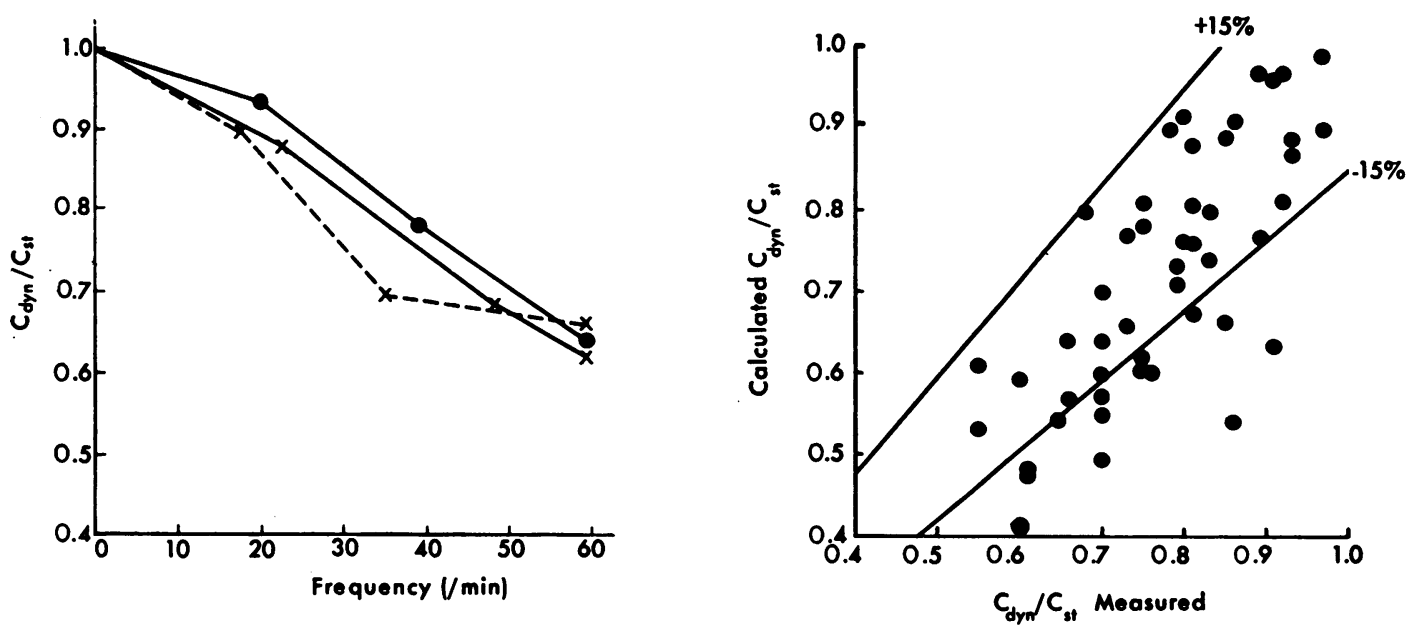

FIGURE 4 Comparison of calculated (from $\mathrm{N}_{2}$ washout) and measured $C_{\mathrm{dyn}} / C_{\mathrm{st}}$ in young smokers (group B). (A) A representative case showing calculated and measured $C_{\mathrm{dyn}} / C_{\mathrm{st}}$ as a function of respiratory frequency. Procedure of comparison as in Fig. 3. (B) Identity comparison of calculated and measured $C_{\mathrm{dyn}} / C_{\mathrm{st}}$ for all nine subjects at respiratory frequencies of 20,40 , and $60 / \mathrm{min}$.

tribution of ventilation was demonstrated at both respiratory rates.

\section{DISCUSSION}

In the present investigation, a good agreement was found between calculated $C_{\mathrm{dyn}} / C_{\text {st }}$ and actually measured $C_{\mathrm{dyn}} / C_{\text {st }}$ in mechanically ventilated dogs with partial obstruction of one main bronchus, in young subjects with artificially induced airway obstruction (carbachol), and in asymptomatic young smokers. In dogs, in the presence of unequal time constants, distribution of ventilation expressed as $\mathrm{N}_{2}$ clearance delay increased as $C_{\text {dyn }}$ decreased with increasing frequency. This confirms the experimental findings that Ingram and Schilder (5) obtained in humans. In the human experiments where $C_{\text {st }}$ was determined from the deflation leg of the static pressure volume curve for comparison to $C_{\mathrm{dyn}}$, systematic overestimation of frequency dependence of compliance could be expected because of the difference in volume history. However, the lack of frequency dependence of compliance in normal subjects indicated that this overestimation was slight. Furthermore, the degree of such an error would be expected to decrease with increasing respiratory frequency.

The influence of Pendelluft, which, if the time constants are sufficiently different, increases to a maximum and returns to a minimum at high respiratory frequencies, and of the common dead space on alveolar mixing must be considered in the calculations of
$C_{\mathrm{dyn}} / C_{\text {st }}$ from the compartmental analysis of the $\mathrm{N}$ washout curve. According to Safonoff and Emmanue (8) these factors produce a significant underestimation of the alveolar ventilation of the fast and slight overestimation of the ventilation of the slow compartment. Using their experimentally obtained correction factor to convert the apparent ventilation of the fast compartment to its actual alveolar ventilation, our calculated $C_{\mathrm{dyn}} / C_{\text {st }}$ from the $\mathrm{N}_{2}$ washout curve correlated well with the measured $C_{\mathrm{dyn}} / C_{\mathrm{st}}$. Since this is only an approximate correction factor (8), and the effect of Pendelluft and common dead space mixing reach a minimum as the difference between the compartmental alveolar ventilation increases, it is not surprising that the accuracy of the predicted $C_{\mathrm{dyn}} / C_{\mathrm{st}}$ was better at higher respiratory frequencies (see Appendix A). A further theoretical objection to equating the compartmental to total tidal volume ratio $\left(V_{\mathrm{T}_{1}} / V_{\mathrm{T}}\right)$ with the compartmental to total alveolar ventilation ratio $\left(\dot{V}_{\mathbf{A}_{1}} / \dot{V}_{\mathbf{A}}\right)$ is the presence of common dead space $\left(V_{\mathrm{D}}\right)$ and compartmental dead spaces $\left(V_{\mathrm{D}_{1}}, V_{\mathrm{D}_{2}}\right)$ which have to be subtracted from the tidal volumes for the calculation of alveolar ventilation:

$$
\frac{\left(V_{T_{1}}-V_{D_{1}}\right) \times f}{\left(V_{T}-V_{D}\right) \times f}=\frac{\dot{V}_{A_{1}}}{\dot{V}_{A}}
$$

Since $V_{\mathrm{T}_{1}} / V_{\mathrm{T}}$ changes with both increasing respiratory frequencies and increasingly uneven compartmental time constants, but $V_{D_{1}}$ and $V_{\mathrm{D}}$ are more or less of constant value, an error is introduced into Eq. 15. 
TABLE II

Anthropometric Data, Symptoms, Pulmonary Function Tests, and Nitrogen Clearance Delay in Young Smokers (Group C)

\begin{tabular}{|c|c|c|c|c|c|c|c|c|c|c|c|c|c|c|}
\hline \multirow[b]{3}{*}{ Subject } & \multirow{3}{*}{$\begin{array}{l}\text { Age, } \\
\text { sex }\end{array}$} & \multirow[b]{3}{*}{ Height } & \multirow{3}{*}{$\begin{array}{c}\text { Packs/ } \\
\text { day } \\
\text { year }\end{array}$} & \multirow[b]{3}{*}{ Sputum } & \multirow[b]{3}{*}{ Dyspnea } & \multicolumn{9}{|c|}{ Pulmonary function tests* } \\
\hline & & & & & & \multirow[b]{2}{*}{$\mathrm{vC}$} & \multirow[b]{2}{*}{ FRC } & \multirow[b]{2}{*}{ RV } & \multirow[b]{2}{*}{ TLC } & \multirow[b]{2}{*}{ FEV $_{1.0}$} & \multirow[b]{2}{*}{ Raw } & \multirow[b]{2}{*}{ Di.co } & \multicolumn{2}{|c|}{ NCD } \\
\hline & & & & & & & & & & & & & 60 & 75 \\
\hline & & $\mathrm{cm}$ & & & & & & & & & & & & \\
\hline 1 & $28 \mathrm{M}$ & 185.0 & 5 & No & No & 93 & 73 & 76 & 88 & 104 & 146 & 82 & 33 & 36 \\
\hline 2 & $36 \mathrm{M}$ & 172.6 & 40 & No & No & 107 & 80 & 76 & 98 & 89 & 125 & 102 & 37 & 12 \\
\hline 3 & $23 \mathrm{M}$ & 175.5 & 10 & Yes & Yes & 96 & 84 & 68 & 92 & 102 & 182 & 94 & 31 & 37 \\
\hline 4 & $23 \mathrm{M}$ & 177 & 3 & No & No & 97 & 82 & 64 & 89 & 93 & 141 & 85 & 0 & 8 \\
\hline 5 & $28 \mathrm{~F}$ & 162.5 & 7 & No & Yes & 107 & 82 & 80 & 99 & 86 & 120 & 89 & 28 & 8 \\
\hline 6 & $28 \mathrm{M}$ & 168.5 & 1 & No & No & 102 & 91 & 105 & 96 & 93 & 183 & 88 & 0 & 10 \\
\hline 7 & $26 \mathrm{M}$ & 187.0 & 3 & Yes & No & 97 & 78 & 67 & 88 & 92 & 154 & 106 & 26 & 20 \\
\hline 8 & $42 \mathrm{M}$ & 167.5 & 8 & No & No & 102 & 105 & 123 & 108 & 91 & 176 & 107 & 51 & 93 \\
\hline 9 & $21 \mathrm{M}$ & 175 & 7 & No & Yes & 90 & 90 & 101 & 93 & 84 & 226 & 116 & 20 & 18 \\
\hline 10 & $18 \mathrm{M}$ & 180 & 5 & No & No & 87 & 76 & 69 & 83 & 85 & 223 & 100 & 0 & 22 \\
\hline Means & 27.3 & & 8.9 & & & 97.8 & 84.1 & 82.9 & 93.4 & 91.9 & 167.6 & 96.9 & & \\
\hline Range & $18-42$ & & $1-40$ & & & $87-107$ & $73-105$ & $64-123$ & $83-108$ & $84-104$ & $125-226$ & $82-116$ & & \\
\hline
\end{tabular}

VC, vital capacity; FRC, functional residual capacity; RV, residual volume; TLC, total lung capacity; FEV ${ }_{1.0}$, forced expiratory volume in $1 \mathrm{~s}$; RAw, airway resistance; DLco, diffusing capacity of the lung for $\mathrm{CO} ; \mathrm{NCD}$, nitrogen clearance delay in percent at 60 and $75 \mathrm{breaths} / \mathrm{min}$.

* Percent predicted normal (see text).

However, if the distribution of dead spaces approximates the distribution of tidal volumes, or

$$
\frac{V_{D_{1}}}{V_{D}} \cong \frac{V_{T_{1}}}{V_{T}}
$$

then the dead space effect can be neglected. This assumption is probably valid in the case of small airway disease because of the negligible effects on dead space volume in this condition.

While it was expected that the theoretical predictions based on a two-compartment system would hold true in dogs with partial obstruction of one lung whose gas mixing appears to be ideal because of extensive collateral ventilation (20), there was also a close correlation between calculated and measured $C_{\mathrm{dyn}} / C_{\mathrm{st}}$ in the human lung. Since our analysis requires that the two compartments show normal elastic properties, it is mostly applicable to healthy subjects or those with minimal lung disease. The relationships between the $\mathrm{N}_{2}$ washout curve and frequency dependence of lung compliance would be less ideal in more advanced lung disease with large differences in elastic properties among various lung units.

TABLE III

Anthropometric Data, Symptoms, Pulmonary Function Tests, and Nitrogen Clearance Delay in Young Nonsmokers (Group C)

\begin{tabular}{|c|c|c|c|c|c|c|c|c|c|c|c|c|c|c|}
\hline \multirow[b]{3}{*}{ Subject } & \multirow{3}{*}{$\begin{array}{c}\text { Age, } \\
\text { sex }\end{array}$} & \multirow[b]{3}{*}{ Height } & \multirow{3}{*}{$\begin{array}{c}\text { Packs/ } \\
\text { day } \\
\text { year }\end{array}$} & \multirow[b]{3}{*}{ Sputum } & \multirow[b]{3}{*}{ Dyspnea } & \multicolumn{9}{|c|}{ Pulmonary function tests* } \\
\hline & & & & & & \multirow[b]{2}{*}{$\mathrm{VC}$} & \multirow[b]{2}{*}{ FRC } & \multirow[b]{2}{*}{ RV } & \multirow[b]{2}{*}{ TLC } & \multirow[b]{2}{*}{$\mathrm{FEV}_{1.0}$} & \multirow[b]{2}{*}{ RAw } & \multirow[b]{2}{*}{ DLco } & \multicolumn{2}{|c|}{ NCD } \\
\hline & & & & & & & & & & & & & 60 & 75 \\
\hline & & $c m$ & & & & & & & & & & & & \\
\hline 1 & $22 \mathrm{M}$ & 180.5 & 0 & No & No & 115 & 105 & 103 & 112 & 106 & 162 & 98 & 0 & 0 \\
\hline 2 & $32 \mathrm{M}$ & 183 & 0 & No & No & 85 & 101 & 97 & 89 & 101 & 116 & 118 & 0 & 0 \\
\hline 3 & $26 \mathrm{M}$ & 185.0 & 0 & No & No & 105 & 115 & 113 & 107 & 91 & 185 & 109 & 0 & 0 \\
\hline 4 & $27 \mathrm{M}$ & 175 & 0 & No & No & 97 & 84 & 94 & 96 & 102 & 113 & 97 & 0 & 0 \\
\hline 5 & $35 \mathrm{~F}$ & 170 & 0 & No & No & 104 & 101 & 114 & 107 & 96 & 96 & 73 & 0 & 0 \\
\hline 6 & $28 \mathrm{M}$ & 180 & 0 & No & No & 102 & 80 & 82 & 96 & 90 & 120 & 103 & 0 & 0 \\
\hline 7 & $29 \mathrm{M}$ & 175 & 0 & No & No & 127 & 90 & 97 & 119 & 119 & 150 & 130 & 0 & 0 \\
\hline 8 & $28 \mathrm{M}$ & 187.5 & 0 & No & No & 92 & 98 & 106 & 96 & 90 & 146 & 108 & 0 & 0 \\
\hline 9 & $31 \mathrm{M}$ & 173.0 & 0 & No & No & 104 & 86 & 101 & 103 & 95 & 116 & 97 & 0 & 0 \\
\hline 10 & $25 \mathrm{M}$ & 177 & 0 & No & No & 134 & 99 & 49 & 112 & 117 & 206 & 128 & 0 & 0 \\
\hline Means & 28.1 & & & & & 106.5 & 95.9 & 95.6 & 103.7 & 100.7 & 141.0 & 106.1 & & \\
\hline Range & $22-35$ & & & & & $85-134$ & $80-115$ & 49-114 & $89-119$ & $90-119$ & $96-206$ & $73-130$ & & \\
\hline
\end{tabular}

VC, vital capacity; FRC, functional residual capacity; RV, residual volume; TLC, total lung capacity; FEC ${ }_{1.0}$, forced expiratory volume in $1 \mathrm{~s}$; RAw, airway resistance; DLco, diffusing capacity of the lung for CO; NCD, nitrogen clearance delay in percent at 60 and $75 \mathrm{breaths} / \mathrm{min}$.

* Percent predicted normal (see text). 
Single Breath $\mathrm{N}_{2}$ Test
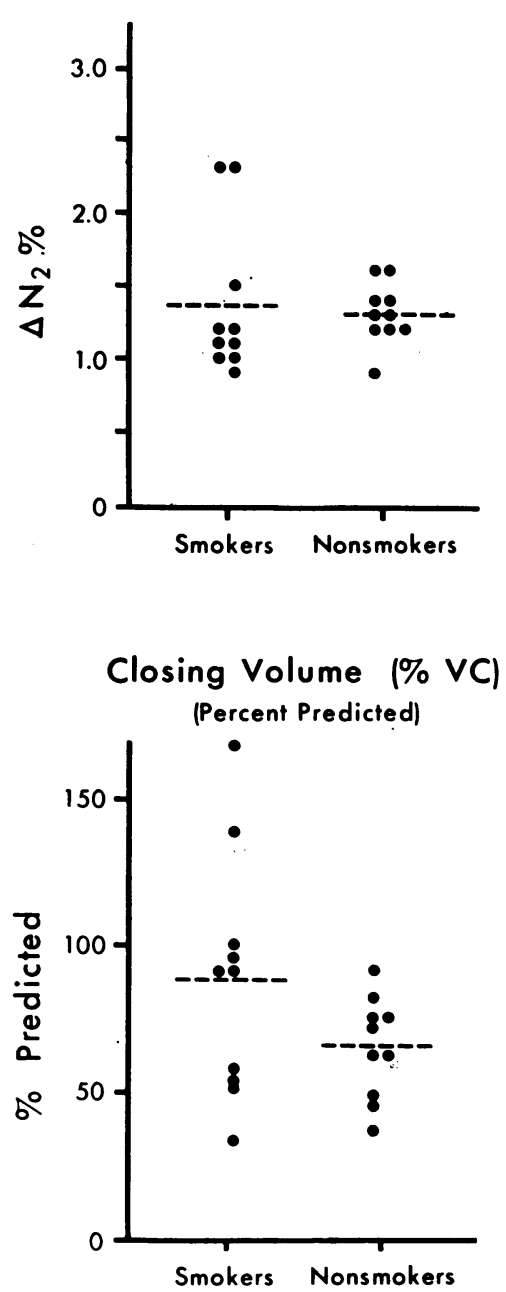

\section{Flow at $50 \%$ Vital Capacity}

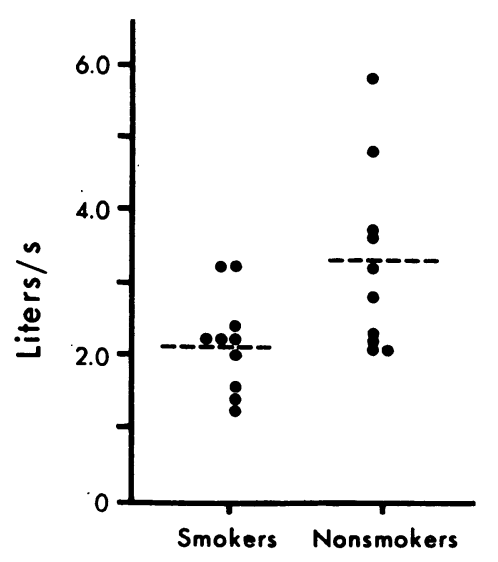

Closing Volume in Liters

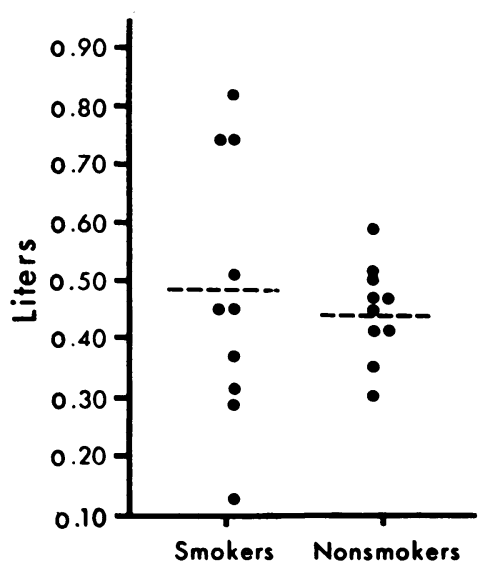

FIGURE 5 Comparison of commonly used screening tests for early lung disease among 10 healthy young smokers and 10 healthy nonsmokers (group $\mathrm{C}$ ). The predicted normal values for closing volume are taken from McCarthy, Spencer, Greene, and Milic-Emili (23).

Since Woolcock, Vincent, and Macklem (2) introduced frequency dependence of lung compliance as a test for small airway obstruction and indicated that frequency dependence of $C_{\mathrm{dyn}}$ is associated with frequency dependence of distribution of ventilation, this has been confirmed by others $(4,5)$. On the basis of Ingram and O'Cain's (21) study on frequency dependence of $C_{\mathrm{dyn}}$ in asymptomatic smokers, we expected to find a difference in $\mathrm{N}_{2}$ washout at high respiratory frequencies between our young smokers and nonsmokers. While the nonsmokers had a single exponential $\mathrm{N}_{2}$ washout curve, all 10 smokers revealed two compartments at one or both measured respiratory frequencies. Our finding that all nonsmokers had a single exponential curve contrasts with Bouhuys (22) who found a mean $\mathrm{N}_{2}$ clearance delay of $29 \%$ in young subjects between 24 and $34 \mathrm{yr}$ of age at normal respiratory rates. However, it is not quite clear from his data whether smokers were included as normal subjects.

In our subjects, of two other tests which have been employed to detect small airway obstruction, the closing volume (23) showed no significant difference between nonsmokers and smokers, whereas maximum expiratory flow at $50 \%$ of vital capacity was significantly lower in smokers than in nonsmokers. However, the scatter of data minimizes the discriminatory value of this test in individual young smokers with small airway obstruction. In contrast, the $\mathrm{N}_{2}$ clearance delay was $0 \%$ in all nonsmokers and deviated from $0 \%$ in all young smokers at rapid respiratory frequencies. 
A number of theoretical and technical reasons can be listed for the observed discrepancies between calculated and measured $C_{\mathrm{dyn}} / C_{\mathrm{st}}$ in our smokers and normal subjects challenged with carbachol. First, the influence of boundary diffusion on alveolar mixing was not taken into account. It is evident that diffusion of gases takes place between the dead space and gas exchange units and that this diffusion factor decreases as frequency is increased. Although Roos, Dahlstrom, and Murphy (24) indicated that boundary diffusion may have a significant effect on alveolar mixing, it was not considered in our analysis because we had no way to quantitate it. Our employment of Otis' (1) model which neglects parallel airway compliance (25), and our assumption of a sinusoidal input may have introduced error into the calculations. We further assumed that time constants are not altered with changes in respiratory frequencies. However, in the human lung with a large number of uneven time constants, all the resistances may not be linear and all the compliances may not be operating on the linear portion of the static pressure-volume curve at all respiratory frequencies with the result that the compartmental time constants may actually differ during the two $\mathrm{N}_{2}$ runs. Further, a slight increase in FRC during the run may have occurred despite careful monitoring of the end-expiratory volume level and consequently produced an artifactual slow compartment. On the other hand, slight changes in tidal volumes during a run probably do not affect the calculation of distribution of ventilation, since $\mathrm{N}_{2}$ concentration was plotted against cumulative expired volume. The extrapolation of a two-compartment system to the abnormal lung with a large number of uneven time constants also introduces some degree of error. Indeed, examination of Table I, shows that the fractional compartmental volume did not remain the same for the two breathing frequencies in all subjects. Also the ratio of $\dot{V}_{\mathbf{A}_{1}} / \dot{V}_{\mathbf{A}_{2}}$ did not increase with frequency in all cases. The arbitrary fitting of two components to the nitrogen washout curve in a multicompartment system with a continuum of time constants might have merged individual compartments with intermediate time constants either in the slow or fast compartment, depending on respiratory frequency. In addition to the inaccuracy introduced by the fitting of a two-component curve, in the normal subjects after carbachol the short duration of action of this drug could have caused a change in the degree of airway obstruction between the two $\mathrm{N}_{2}$ washout determinations. This probably occurred since the data for this group was less consistent than in the healthy smokers. Despite all these theoretical objections to analysis of the $\mathrm{N}_{2}$ washout curve, experimental data in dogs and humans indicated good agreement between calculated (from $\mathrm{N}_{2}$ washout curves) and actually measured $C_{\mathrm{dyn}} / C_{\mathrm{st}}$.

The $\mathrm{N}_{2}$ washout method performed at higher respiratory frequencies appears to be an excellent screening test for the detection of mild uneveness of distribution of ventilation occurring in early lung disease. Considering the possible discrepancies between frequency dependence of compliance and distribution of ventilation, the $\mathrm{N}_{2}$ washout technique which measures directly gas distribution and indirectly $C_{\mathrm{dyn}} / C_{\mathrm{st}}$ may be preferable to the conventional determination of $\mathrm{dy}$ namic lung compliance.

\section{APPENDIX A}

Determination of Average $V_{p} / V_{\mathrm{T}_{2}}$ and its Effect on Calculated $C_{\mathrm{dyn}} / C_{\mathrm{st}}$

From Otis et al. (1) we can express the ratio of the volume of Pendelluft $\left(V_{p}\right)$ to the tidal volume of the slow compartment $\left(V_{\mathrm{T}_{2}}\right)$ by the expression:

$$
\frac{V_{p}}{V_{T_{2}}}=\frac{Z_{T}\left(Z_{1}+Z_{2}\right)-Z_{1} Z_{2}}{Z_{1} Z_{T}}
$$

where $Z_{1}=$ impedance of fast compartment, $Z_{2}=$ impedance of slow compartment, and $Z_{\mathrm{T}}$ is the total impedance of the two parallel compartments. The impedances are dependent on frequency, resistance, and compliance, where resistance and compliance are also functions of the compartmental volumes.

A program was written in FORTRAN language, for use on a PDP-12 computer to evaluate the average value of this ratio $\left(V_{p} / V_{\mathrm{T}_{2}}\right)$ and the percent error in the calculated $C_{\mathrm{dyn}} / C_{\mathrm{st}}$ caused by assuming the ratio to be equal to 0.60 for various airway resistances, compartmental volumes, and breathing frequencies, assuming the case of equal elastic properties of the two compartments. The program consisted of three "nested DO-loops" in which the parameters were varied in the ranges of interest (frequency from 20 to $80 / \mathrm{min}$, increments of $10 / \mathrm{min}$, fractional volumes of each compartment from 0.10 to 0.90 , increments of 0.05 , and resistance of the slow compartment from $10 \mathrm{~cm} \mathrm{H} \mathrm{H}_{2} \mathrm{O} /$ liter/s to $100 \mathrm{~cm} \mathrm{H}_{2} \mathrm{O}$ / liter/s). The fixed parameters were chosen to approximate normal values for humans $\left(C_{\mathrm{st}}=0.20 \mathrm{liter} / \mathrm{cm} \mathrm{H} \mathrm{H}_{2} \mathrm{O}\right.$, small airway resistance $=0.30 \mathrm{~cm} \mathrm{H}_{2} \mathrm{O} /$ liter/s). The range of resistance in the slow compartment was chosen to coincide with the limits of the $\mathrm{N}_{2}$ washout methods in detecting twocompartmental washouts.

The mean values and standard deviations of $V_{p} / V_{T_{2}}$ are shown at different breathing frequencies in Fig. A-1A. This curve was generated by 2,261 samples. As can be seen, the accuracy of the ratio of $V_{p} / V_{\mathrm{T}_{2}}$ increases with increasing frequencies. This is due to the fact that at lower frequencies $V_{p}$ is increasing from zero while $V_{\mathrm{T}_{2}}$ is decreasing. At a threshold frequency $V_{p}$ reaches a maximum and begins to decrease at a rate similar to the decrease in $V_{T_{2}}$. This phenomenon is illustrated in Fig. A-1B for the particular case where $T_{1}=0.1 \mathrm{~s}$ and $T_{2}=3.2 \mathrm{~s}$ : If respiratory frequency is kept between 50 and 80 breaths/min, the mean value for $V_{p} / V_{\mathrm{T}_{2}}$ is 0.55 , SD 0.08 , range $0.18-0.67$. This value supports the experimental findings of Safonoff and Emmanuel (8). Based on these considerations, frequencies in the range of 50-80 breaths/min were employed for the calculation of $C_{\mathrm{dyn}} / C_{\mathrm{st}}$ from the $\mathrm{N}_{2}$ washout curves. The mean percent 

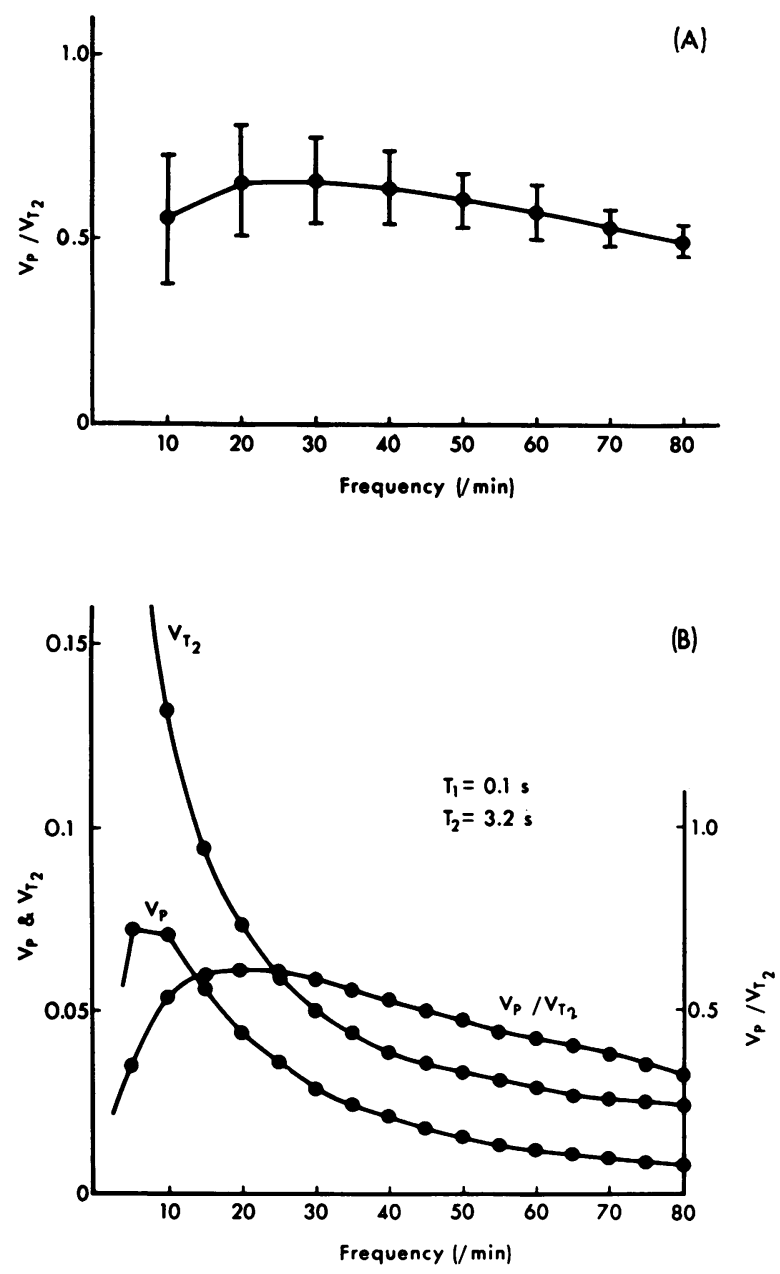

FIGURE A-1 (A) Results of FOCAL program showing mean values \pm 1 standard deviation (brackets) of $V_{p} / V_{\mathrm{T}_{2}}$ for frequencies from $10 / \mathrm{min}$ to $80 / \mathrm{min}$. $V_{\mathrm{T}_{2}}$ is the tidal volume of the "slow" compartment and $V_{p}$ is the volume of Pendelluft. $(B)$ Behavior of the two compartmental system for the case where $T_{1}=0.1 \mathrm{~s}$ and $T_{2}=3.2 \mathrm{~s}$.

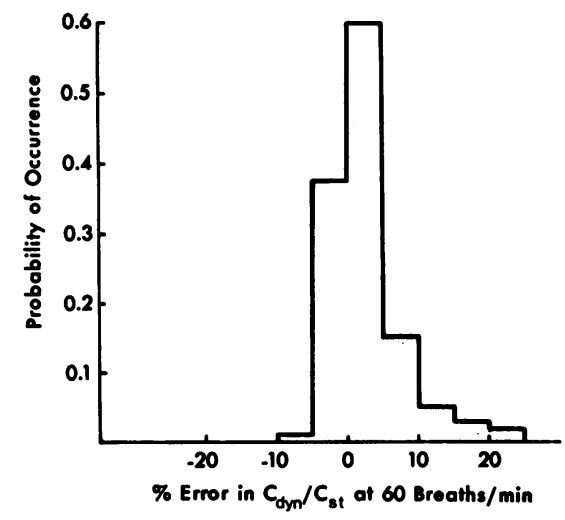

Figure A-2 Distribution of percent error in $C_{\mathrm{dyn}} / C_{\mathrm{st}}$ at $60 /$ min caused by the assumption that $V_{p} / V_{\mathrm{T}_{2}}=0.60$. error in $C_{\mathrm{dyn}} / C_{\text {st }}$ at 60 breaths/min caused by the assumption that $V_{p} / V_{\mathrm{T}_{2}}=0.60$ was $0.5 \%$, SD 2.0 , range $-6.4 \%$ to $21.4 \%$. The distribution of this percent error is illustrated in Fig. A-2. These values were determined by using the equations of Safonoff and Emmanuel (8) to compute the apparent ventilations from the actual ventilations and the actual volume of Pendelluft. These apparent ventilations were then corrected by using the assumption that $V_{p} / V_{\mathrm{T}_{2}}=0.60$. Then $C_{\mathrm{dyn}} / C_{\mathrm{st}}$ was determined as described in the theoretical considerations and was compared to $C_{\mathrm{dyn}} / C_{\mathrm{st}}$ calculated from Otis' equations (1) by using the actual values for time constants, compliances, and fractional volumes.

\section{APPENDIX B}

Solutions to the equations for the time constants of the two-compartment lung model (see Eqs. 3 and 4)

From Otis et al. (1) we have:

$$
\begin{gathered}
C_{\mathrm{dyn}}=\frac{\omega^{2}\left(T_{2} C_{1}+T_{1} C_{2}\right)^{2}+\left(C_{1}+C_{2}\right)^{2}}{\omega^{2}\left(T_{1}^{2} C_{2}+T_{2}^{2} C_{1}\right)+\left(C_{1}+C_{2}\right)} \\
V_{T_{1}}=V_{T} Z_{T} / Z_{1} \\
V_{T_{2}}=V_{T} Z_{T} / Z_{2}
\end{gathered}
$$

But,

$$
\begin{aligned}
& Z_{1}=\left(R_{1}^{2}+\frac{1}{\omega^{2} C_{1}^{2}}\right)^{\frac{1}{2}}=\frac{1}{C_{1}}\left(T_{1}^{2}+\frac{1}{\omega^{2}}\right)^{\frac{1}{2}} \\
& Z_{2}=\left(R_{2}{ }^{2}+\frac{1}{\omega^{2} C_{2}^{2}}\right)^{\frac{1}{2}}=\frac{1}{C_{2}}\left(T_{2}^{2}+\frac{1}{\omega^{2}}\right)^{\frac{1}{2}} \\
& Z_{T}=\frac{Z_{1} Z_{2}}{\left|\bar{Z}_{1}+\bar{Z}_{2}\right|}
\end{aligned}
$$

Turning our attention to Eq. B3,

$$
\begin{aligned}
\left|\bar{Z}_{1}+\bar{Z}_{2}\right|=\left[\left(Z_{1} \cos \theta_{1}\right.\right. & \left.+Z_{2} \cos \theta_{2}\right)^{2} \\
& \left.+\left(Z_{1} \sin \theta_{1}+Z_{2} \sin \theta_{2}\right)^{2}\right]^{\frac{1}{2}}
\end{aligned}
$$

where $\theta_{1}, \theta_{2}$ are the phase angles of $Z_{1}, Z_{2}$. Eq. B4 reduces to

$$
\begin{aligned}
\left|\bar{Z}_{1}+\bar{Z}_{2}\right|= & {\left[Z_{1}^{2}+Z_{2}^{2}\right.} \\
& \left.+2 Z_{1} Z_{2}\left(\cos \theta_{1} \cos \theta_{2}+\sin \theta_{1} \sin \theta_{2}\right)\right]^{\frac{1}{2}}
\end{aligned}
$$

Now, since $\tan \theta_{n}=1 / \omega T_{n}$ by definition,

$$
\begin{aligned}
& \sin \theta_{1}=1 /\left(1+\omega^{2} T_{1}^{2}\right)^{\frac{1}{2}} \\
& \cos \theta_{1}=\omega T_{1} /\left(1+\omega^{2} T_{1}^{2}\right)^{\frac{1}{2}} \\
& \sin \theta_{2}=1 /\left(1+\omega^{2} T_{2}^{2}\right)^{\frac{1}{2}} \\
& \cos \theta_{2}=\omega T_{2} /\left(1+\omega^{2} T_{2}^{2}\right)^{\frac{1}{2}}
\end{aligned}
$$

Then, substituting these relations into Eq. B5 and rearranging gives

$$
\begin{aligned}
\left|\bar{Z}_{1}+\bar{Z}_{2}\right| & \\
= & \left(Z_{1}^{2}+Z_{2}^{2}+\frac{2 Z_{1} Z_{2}\left(T_{1} T_{2}+\frac{1}{\omega^{2}}\right)}{\left(T_{1}^{2}+\frac{1}{\omega^{2}}\right)^{\frac{1}{2}}\left(T_{2}^{2}+\frac{1}{\omega^{2}}\right)^{\frac{1}{2}}}\right)^{\frac{1}{2}}
\end{aligned}
$$


Substituting Eqs. $\mathrm{B} 1$ and $\mathrm{B} 2$ for $Z_{1}$ and $Z_{2}$ in Eq. $\mathrm{B} 7$ gives

$$
\begin{aligned}
\left|\bar{Z}_{1}+\bar{Z}_{2}\right|=\left(\frac{\left(T_{1}{ }^{2}+\frac{1}{\omega^{2}}\right)}{C_{1}{ }^{2}}+\right. & \frac{\left(T_{2}{ }^{2}+\frac{1}{\omega^{2}}\right)}{C_{2}{ }^{2}} \\
+ & \left.2 \frac{\left(T_{1} T_{2}+\frac{1}{\omega^{2}}\right)}{C_{1} C_{2}}\right)^{\frac{1}{2}}
\end{aligned}
$$

Substituting Eqs. B8, B1, and B2 into Eqs. 3 and 4 gives

$$
\begin{aligned}
& \frac{V_{T_{1}}}{V_{T}}=\frac{\frac{1}{C_{2}}\left(T_{2}^{2}+\frac{1}{\omega^{2}}\right)^{\frac{1}{2}}}{\left(\frac{\left(T_{1}^{2}+\frac{1}{\omega^{2}}\right)}{C_{1}{ }^{2}}+\frac{\left(T_{2}^{2}+\frac{1}{\omega^{2}}\right)}{C_{2}{ }^{2}}+2 \frac{\left(T_{1} T_{2}+\frac{1}{\omega^{2}}\right)}{C_{1} C_{2}}\right)^{\frac{1}{2}}} \\
& \frac{V_{T_{2}}}{V_{T}}=\frac{\frac{1}{C_{1}}\left(T_{1}^{2}+\frac{1}{\omega^{2}}\right)^{\frac{1}{2}}}{\left(\frac{\left(T_{1}{ }^{2}+\frac{1}{\omega^{2}}\right)}{C_{1}{ }^{2}}+\frac{\left(T_{2}{ }^{2}+\frac{1}{\omega^{2}}\right)}{C_{2}{ }^{2}}+2 \frac{\left(T_{1} T_{2}+\frac{1}{\omega^{2}}\right)}{C_{1} C_{2}}\right)^{\frac{1}{2}}}
\end{aligned}
$$

Assuming that $C_{1}=n_{1} C_{\mathrm{st}}$ and $C_{2}=n_{2} C_{\mathrm{st}}$, as stated in the Theoretical Considerations, and substituting these expressions for $C_{1}$ and $C_{2}$ into Eqs. 2, 6, and 7 gives

$$
\begin{aligned}
& \frac{C_{\mathrm{dyn}}}{C_{\mathrm{st}}}=\frac{\omega^{2}\left(n_{2} T_{1}+n_{1} T_{2}\right)^{2}+1}{\omega^{2}\left(n^{2} T_{1}^{2}+n_{1} T_{2}^{2}\right)+1} \\
& \frac{V_{T_{1}}}{V_{T}}=\frac{n_{1}\left(T_{2}^{2}+\frac{1}{\omega^{2}}\right)^{\frac{1}{2}}}{\left[\left(n_{2} T_{1}+n_{1} T_{2}\right)^{2}+\frac{1}{\omega^{2}}\right]^{\frac{1}{2}}} \\
& \frac{V_{T_{2}}}{V_{T}}=\frac{n_{2}\left(T_{1}^{2}+\frac{1}{\omega^{2}}\right)^{\frac{1}{2}}}{\left[\left(n_{2} T_{1}+n_{1} T_{2}\right)^{2}+\frac{1}{\omega^{2}}\right]^{\frac{1}{2}}}
\end{aligned}
$$

From the analysis of $\mathrm{N}_{2}$ washout curves we have values for $n_{1}$ and $n_{2}$, and estimates of $V_{T_{1}} / V_{T}$ and $V_{T_{2}} / V_{T}$ :

$$
\frac{V_{T_{1}}}{V_{T}} \cong \frac{\dot{V}_{A_{1}}}{\dot{V}_{A}}
$$

and

$$
\frac{V_{T_{2}}}{V_{T}} \cong \frac{\dot{V}_{A_{2}}}{\dot{V}_{A}}
$$

Thus Eqs. 9 and 10 can be solved simultaneously for $T_{1}$ and $T_{2}$. For simplicity, we let

$$
\begin{aligned}
& V_{1}=\left(\frac{V_{T_{1}}}{V_{T}}\right)^{2} \cong\left(\frac{\dot{V}_{A_{1}}}{\dot{V}_{A}}\right)^{2} V_{2}=\left(\frac{V_{T_{2}}}{V_{T}}\right)^{2} \cong\left(\frac{\dot{V}_{A_{2}}}{\dot{V}_{A}}\right)^{2} \\
& T_{A}=n_{2} T_{1} \quad T_{B}=n_{1} T_{2}
\end{aligned}
$$

Then

$$
\begin{gathered}
V_{1}=\frac{T_{B}^{2}+\frac{n_{1}^{2}}{\omega^{2}}}{\left(T_{A}+T_{B}\right)^{2}+\frac{1}{\omega^{2}}} \\
V_{2}=\frac{T_{A}^{2}+\frac{n_{2}^{2}}{\omega^{2}}}{\left(T_{A}+T_{B}\right)^{2}+\frac{1}{\omega^{2}}}
\end{gathered}
$$

or

$$
\begin{aligned}
& \left(T_{A}+T_{B}\right)^{2}=\frac{T_{B}^{2}}{V_{1}}+\left(\frac{n_{1}{ }^{2}}{V_{1} \omega^{2}}-\frac{1}{\omega^{2}}\right) \\
& \left(T_{A}+T_{B}\right)^{2}=\frac{T_{A}^{2}}{V_{2}}+\left(\frac{n_{2}{ }^{2}}{V_{2} \omega^{2}}-\frac{1}{\omega^{2}}\right)
\end{aligned}
$$

Now, if we let

$$
\begin{aligned}
& X_{1}=\left(\frac{n_{1}{ }^{2}}{V_{1} \omega^{2}}-\frac{1}{\omega^{2}}\right) \\
& X_{2}=\left(\frac{n_{2}^{2}}{V_{2} \omega^{2}}-\frac{1}{\omega^{2}}\right)
\end{aligned}
$$

and equate the right hand sides of Eqs. B11, then

$$
\frac{T_{B}^{2}}{V_{1}}+X_{1}=\frac{T_{A}^{2}}{V_{2}}+X_{2}
$$

rearranging gives

$$
T_{A}=\left(B T_{B}^{2}+A\right)^{\frac{1}{2}}
$$

where $A=V_{2}\left(X_{1}-X_{2}\right)$ and $B=\left(V_{2} / V_{1}\right)$. Substituting Eq. B13 for $T_{A}$ in Eq. B11 gives

$$
\left[\left(B T_{B}^{2}+A\right)^{\frac{1}{2}}+T_{B}\right]^{2}=\frac{T_{B}^{2}}{V_{1}}+X_{1}
$$

Expanding and rearranging gives

$$
\begin{aligned}
\frac{\left(X_{1}-A\right)}{2}-T_{B}{ }^{2}\left(\frac{B+1-\frac{1}{V_{1}}}{2}\right) & \\
& =T_{B}\left(B T_{B}{ }^{2}+A\right)^{\frac{1}{2}}
\end{aligned}
$$

Letting

$$
C=\frac{B+1-\frac{1}{V_{1}}}{2}
$$

and

$$
D=\frac{X_{1}-A}{2}
$$

and squaring both sides of Eq. B15 gives

$$
D^{2}-2 D C T_{B}^{2}+C^{2} T_{B}^{4}=T_{B}^{2}\left(B T_{B}^{2}+A\right)
$$


or

$$
T_{B}{ }^{4}+\left(\frac{A+2 D C}{B-C^{2}}\right) T_{B}{ }^{2}-\left(\frac{D^{2}}{B-C^{2}}\right)=0
$$

Letting

$$
Y=\frac{A+2 D C}{B-C^{2}}
$$

and

$$
Z=\frac{D^{2}}{B-C^{2}}
$$

and solving Eq. B17 for $T_{B}^{2}$ gives

$$
T_{B}^{2}=\frac{-Y \pm\left(Y^{2}+4 Z\right)^{\frac{1}{2}}}{2}
$$

But, since $T_{B}{ }^{2}$ is a positive number, Eq. B18 becomes

$$
T_{B}^{2}=\frac{\left(Y^{2}+4 Z\right)^{\frac{1}{2}}-Y}{2}
$$

then

$$
T_{B}=\left[\frac{\left(Y^{2}+4 Z\right)^{\frac{1}{2}}-Y}{2}\right]^{\frac{1}{2}}
$$

Substituting Eq. B20 for $T_{B}$ in Eq. B13 gives

$$
T_{A}=\left\{B\left[\frac{\left(Y^{2}+4 Z\right)^{\frac{1}{2}}-Y}{2}\right]+A\right\}^{\frac{1}{2}}
$$

Now, since $T_{1}=T_{A} / n_{2}$ and $T_{2}=T_{B} / n_{1}$

$$
\begin{aligned}
& T_{1}=\frac{\left\{B\left[\frac{\left(Y^{2}+4 Z\right)^{\frac{1}{2}}-Y}{2}\right]+A\right\}^{\frac{1}{2}}}{n_{2}} \\
& T_{2}=\frac{\left[\frac{\left(Y^{2}+4 Z\right)^{\frac{1}{2}}-Y}{2}\right]^{\frac{1}{2}}}{n_{1}}
\end{aligned}
$$

where

$$
\begin{aligned}
& A=V_{2}\left(X_{1}-X_{2}\right)=\frac{\dot{V}_{A_{2}}}{\omega^{2}}\left(\frac{n_{1}{ }^{2}}{\dot{V}_{A_{1}}{ }^{2}}-\frac{n_{2}{ }^{2}}{\dot{V}_{A_{2}}{ }^{2}}\right) \\
& B=\frac{V_{2}}{V_{1}}=\left(\frac{\dot{V}_{A_{2}}}{\dot{V}_{A_{1}}}\right)^{2} \\
& Y=\left(\frac{A+2 D C}{B-C^{2}}\right)=\frac{A+\left(\frac{n_{1}{ }^{2} \dot{V}_{A}}{\dot{V}_{A_{1}}{ }^{2} \omega^{2}}-\frac{1}{\omega^{2}}-A\right)\left(\frac{B}{2}-\frac{\dot{V}_{A}{ }^{2}}{2 \dot{V}_{A_{1}}{ }^{2}}+\frac{1}{2}\right)}{B-\left(\frac{B}{2}-\frac{\dot{V}_{A}{ }^{2}}{2 \dot{V}_{A_{1}}{ }^{2}}+\frac{1}{2}\right)^{2}} \\
& Z=\frac{D^{2}}{\left(B-C^{2}\right)}=\frac{\left(\frac{n_{1}{ }^{2} \dot{V}_{A 2}}{\dot{V}_{A_{1}}{ }^{2} \omega^{2}}-\frac{1}{\omega^{2}}\right)^{2}}{B-\left(\frac{\mathrm{B}}{2}-\frac{\dot{V}_{A}{ }^{2}}{2 \dot{V}_{A_{1}}{ }^{2}}+\frac{1}{2}\right)^{2}}
\end{aligned}
$$

\section{ACKNOWLEDGMENTS}

The research reported in this paper was sponsored by the Environmental Sciences Division, Aerospace Medical Division, AFSC. United States Air Force, Brooks AFB, Texas, under Contract no. F 41609-72-C-0004 with Mount Sinai Medical Center. In addition, this study was supported by a grant from the National Heart and Lung Institute HL 10622.

\section{REFERENCES}

1. Otis, A. B., C. B. McKerrow, R. A. Bartlett, J. Mead, M. B. McIllroy, N. J. Selverstone, and E. P. Radford. 1956. Mechanical factors in distribution of pulmonary ventilation. J. Appl. Physiol. 8: 427-443.

2. Woolcock, A. J., N. J. Vincent, and P. T. Macklem. 1969. Frequency dependence of compliance as a test for obstruction in the small airways. J. Clin. Invest. 48: 10971105.

3. Defares, J. G., and P. G. Donleben. 1960. Relationship between frequency-dependent compliance and unequal ventilation. J. Appl. Physiol. 15: 166-169.

4. Chiang, S. T. 1971. Distribution of ventilation and frequency-dependence of dynamic lung compliance. Thorax. 26: 721-726.

5. Ingram, R. H., and D. P. Schilder. 1967. Association of a decrease in dynamic compliance with a change in gas distribution. J. Appl. Physiol. 23: 911-916.

6. Chiang, S. T. 1971. Relationship between the time constants of R. C. networks and nitrogen washout in the respiratory system. Aerosp. Med. 42: 1270-1274.

7. Fowler, W. S., E. R. Cornish, Jr., and S. S. Kety. 1952. Lung function studies. VIII. Analysis of alveolar ventilation by pulmonary $\mathrm{N}_{2}$ clearance curves. J. Clin. Invest. 31: 40-50.

8. Safonoff, I., and G. E. Emmanuel. 1967. The effect of Pendelluft and dead space on nitrogen clearance: mathematical and experimental models and their application to the study of the distribution of ventilation. J. Clin. Invest. 46: $1683-1693$.

9. Milic-Emili, J., J. Mead, J. M. Turner, and E. M. Glauser. 1964. Improved technique for estimating pleural pressure from esophageal balloons. J. Appl. Physiol. 19: 207-211.

10. Du Bois, A. B., and L. Dautrebande. 1958. Acute effects of breathing inert dust particles and of carbachol aerosol on the mechanical characteristics of the lungs in man. Changes in response after inhaling sympathomimetic aerosols. J. Clin. Invest. 37: 1746-1755.

11. Du Bois, A. B., S. Y. Botelho, G. N. Bedell, R. Marshall, and J. H. Comroe, Jr. 1952. A rapid plethysmographic method for measuring thoracic gas volume: A comparison with a nitrogen washout method for measuring functional residual capacity in normal subjects. J. Clin. Invest. 31 : 40-50.

12. Du Bois, A. B., S. Y. Botelho, and J. H. Comroe, Jr. 1956. A new method for measuring airway resistance in man using a body plethysmograph: values in normal subjects and in patients with respiratory disease. J. Clin. Invest. 35: 327-335.

13. Ogilvie, C. M., R. E. Forster, W. S. Blakemore, and J. W. Morton. 1957. A standardized breath holding technique for the clinical measurement of the diffusing capacity of the lung for carbon monoxide. J. Ciin. Invest. 36: 1-17.

14. Comroe, J. H., Jr., and W. S. Fowler. 1951. Lung function studies. VI. Detection of uneven alveolar ventilation during a single breath of oxygen. Am. J. Med. 10: 408-413. 
15. Hyatt, R. E., D. P. Schilder, and D. L. Fry. 1958. Relationship between maximum expiratory flow and degree of lung inflation. J. Appl. Physiol. 13: 331-336.

16. Sackner, M. A., and N. D. Atkins. 1972. Pulpac: An Online Data Processing System for Pulmonary Function Testing. Am. Rev. Respir. Dis. 105: 1013-1014.

17. Simmons, D. H., and A. Hemmingway. 1955. Functional residual capacity and respiratory nitrogen excretion in dogs. J. Appl. Physiol. 8: 95-101.

18. Bouhuys, A. 1959. Influence of tissue nitrogen elimination on analysis of pulmonary nitrogen clearance curves. Acta Physiol. Pharmacol Neerl. 8: 431-436.

19. Bates, D. V., P. T. Macklem, and R. V. Christie. 1971. Respiratory Function in Disease. W. B. Saunders Company, Philadelphia. 2nd edition. 92-93.

20. Brown, R., A. J. Woolcock, N. J. Vincent, and P. T. Macklem. 1969. Physiological effects of experimental airway obstruction with beads. J. Appl. Physiol. 27: 328-335.

21. Ingram, R. H., Jr., and C. F. O'Cain. 1971. Frequency dependence of compliance in apparently healthy smokers versus nonsmokers. Bull. Physio-Pathol. Respir. 7: 195-210.

22. Bouhuys, A. 1963. Pulmonary nitrogen clearance in relation to age in healthy males. J. Appl. Physiol. 18: 297-300.

23. McCarthy, D. S., R. Spencer, R. Greene, and J. MilicEmili. 1972. Measurement of "closing volume" as a simple and sensitive test for early detection of small airway disease. Am. J. Med. 52: 747-753.

24. Roos, A., H. Dahlstrom, and J. P. Murphy. 1955. Distribution of inspired air in the lungs. J. Appl. Physiol. 7: 645-659.

25. Mead, J. 1969. Contribution of compliance of airways to frequency-dependent behavior of lungs. J. Appl. Physiol. 26: 670-673. 